\title{
2020 Vision: How a Global Pandemic and the Black Lives Matter Movement Focused our Teaching
}

\author{
Ramsey, Scott \\ Greeson, Kimberley $M$. \\ Affolter, Emily \\ Gano, Gretchen \\ Prescott College, USA \\ Dunbar, Rachel \\ University of West Alabama, USA
}

Doi:10.19044/ejes.v7no4a3 URL:http://dx.doi.org/10.19044/ejes.v7no4a3

\begin{abstract}
Prescott College, a small liberal arts institution in Arizona, offers limited residency Master's and doctoral programs as well as undergraduate programs. Prescott's philosophy centers experiential, community-based, and self-directed learning. While this higher education institution's distancelearning programs are positioned well for broad shifts to online classrooms, we were not without our own struggles to adapt swiftly in Spring 2020. To discover lessons learned and potential strategies of navigating on-going shifts into these uncharted waters, we chronicle how Prescott College's doctoral program adapted its programming in the face of a global pandemic and a racial justice movement that are now issues front and center on the world stage.
\end{abstract}

Keywords: Higher education, online learning, Black Lives Matter, culturally responsive teaching, COVID-19.

\section{Introduction}

2020 Vision: How a Global Pandemic and the Black Lives Matter Movement Focused our Teaching

Prescott College, a small liberal arts institution in Arizona, offers limited-residency Masters and doctoral programs as well as undergraduate programming. Prescott's philosophy centers experiential, community-based, and self-directed learning. While this higher education institution's distance learning programs are positioned well for broad shifts to online classrooms, we, a limited residency doctoral faculty, were not without our own struggles to adapt swiftly in Spring 2020. This article chronicles how Prescott College's 
doctoral program adapted its programming to accommodate a global pandemic and a racial justice movement now issues front and center on the world stage.

In this opinion piece, we bring the pedagogy and educational practices of our doctoral program into conversation with the larger landscape of the COVID-19 pandemic, and more recently, within the context of racial justice in which the killing of George Floyd was, for many, the tipping point. Inspired by an urgent need for an in-depth reflection regarding how to restructure students' learning experiences, we enumerate the ways in which we produce and disseminate knowledge in line with our social and environmental commitments to sustainability as inextricably connected to social justice. We as faculty asked ourselves two questions: 1) How can our curriculum be made accessible, relevant, and meaningful when we are physically distanced from one another and situated in diverse settings and home contexts? 2) To what extent is racial justice centered and advanced through our curricula and how can our instruction positively advance social justice?

\section{Who We are Collectively}

Our collective positionalities as authors have an impact on how and what we teach. The intersecting and diverging identities among us inform and fuel our teaching work and scholarly praxis. Among us, we have a range of dominant and minoritized identities with respect to power, oppression, and privilege. We represent various gender, racial, and ethnic identities. Many of us have caregiver responsibilities for children and other family members. We also represent placed-based geographic diversity within the United States (specifically Hawai'i, Alaska, Washington, Arizona, and Alabama). Sustainability Education is transdisciplinary, and thus, our scholarly training spans education, science and technology studies, and environmental studies and sciences. This range of social identities, lived experiences, and training have fueled our perceptions and pedagogical practices before and through the COVID-19 pandemic.. Our racialized identities play an active role with respect to our accountability for the Black Lives Matter movement and how we believe we can participate meaningfully.

As we endeavor to promote social and environmental justice, we have been intentional in the steps we take to prevent devastation associated with the disadvantages that some groups in our communities may face. Yet, while we recognize that marginalized populations have a history of being neglected socially, professionally, and academically, our focus is not limited to these populations. Rather, in our sustainability curricula, as we strive to ensure that our natural resources are protected, we do so with all in mind. 


\section{Methods}

This piece does not convey formal research methodology in the sense of data collection and analysis. Rather, our methods reflected a synthesis of self-reflection that conveys our shifting pedagogical practices in the last six months. Our team met weekly throughout COVID-19, George Floyd's lynching and beyond, to support each other through implementing emergent and responsive curricula, student support, and symposium planning. This article reflects our own experience of praxis, centering our mutual spirit of collaboration, communication, and adaptation. We began this paper by identifying the Prescott College doctoral program goals, with each of us addressing how our teaching in 2020 manifested itself to align with those goals. Then, the paper's focus moved beyond that organizing structure. Each contributor spent time on this paper both independently and in community, offering suggestions and revisions to further reflect each educator's thinking and distinct positionality. The methods involved writing, revising, discussing, and idea pollinating on our shared experience.

\section{The Spring 2020 Educational Landscape}

In response to the COVID-19 pandemic, educational institutions from primary to higher education made an abrupt shift to online instruction. These adjustments have real and immediate consequences on student psyches and their families as well as broader social and economic impacts. There is little doubt that COVID-19 and, simultaneously, an increased commitment to antiracist praxis (reflection and subsequent action) alter the landscape of higher education, and that many of these shifts will likely endure. Institutions that cannot adapt to this changing backdrop may not survive. While many schools were thrust into reaction mode to immediately offer online courses in the face of the COVID-19 pandemic, colleges and universities already offering limited-residency programming have advantages.

\section{The Backdrop of Distance Learning}

While online learning assumes access to a computer and the internet, which both presume a baseline of economic resources, the distance platform may offer greater student diversity and varied perspectives, potentially enriching learning outcomes. In some instances, online education may equalize access for students that otherwise might be unable to participate in face-to-face classroom settings. Conveniently, they do not need to travel or deviate from their daily schedules in drastic ways to further their education (Dereshiwsky, 2016; Fox, 2017). In addition, the added capacity of this distance-learning platform to offer students the space to think, reflect, and integrate ideas as contrasted to taking lecture notes within a limited time period may contribute to meaningful learning. 
The capacity for Web-based programming to shift to a studentcentered approach also has the potential to promote equity. By creating the space for students to be more involved in their educational journey, they have more of an equal say in creating their individual and collective learning, which creates a democratizing effect on participants (Dhilla, 2017; van Oostveen et al., 2016). We have found that sharing with students this type of agency can promote meaningful learning as students can participate in actively coauthoring courses online that tailor assignments, outcomes, and even assessments to their goals.

\section{Equity and Grace}

While helping students to tailor meaningful goals and outcomes, as Foster et al. (2018) argued, an effective instructor within the online classroom needs to be more engaged and accessible to their students. This is particularly important during unsettling times such as the current pandemic. Schwartz (2020) contended that online instructors increased involvement in students' lives may be particularly important given the need for more connection and reassurance during these sometimes chaotic and fearful times. Schwartz stated,

We now have an essential opportunity to be an authentic solid presence in the lives of others, a vital element of collegiality and leadership even in calm times. When we provide this steady presence, we show students how they might do the same for others. As we engage with students remotely, we construct learning spaces (synchronous and asynchronous), and then through each interaction, we create small moments of big possibility. Every communication has the potential to say: "I see you," "I care," and "You matter." And we are connected, even from afar (para 9).

Such connection is even more apparent with the increased video conferencing with this the global pandemic. It means that facultys' personal lives are as exposed to the public as their students'. Despite Jackson's (2020) discussion of videoclassism, as revealing class discrepancies between students and professors, in many ways, seeing faculty in their homes can likewise positively disrupt the hierarchy that often positions faculty in professional, pedestalized, and somewhat depersonalized office spaces. With personal responsibilities permeating the bounds of student/faculty meetings such as caregiving for children or elders, or the persistent cat in the Zoom frame, we inherently build intimacy with our students and colleagues. The personalization of the learning environment is a reminder to humanize learning and teaching through and beyond the COVID-19 pandemic. While we often invisibly carry our responsibilities in our psyches, they become visible to those with whom we work and learn. These glimpses of personal realities are reminders to think, teach, and act more equitably. If, for example, 
it is difficult to schedule a meeting at a fixed hour because a baby may need care, faculty and students must work together to create a schedule that allows for flexibility. Such cooperation can inspire more grace for faculty and students alike to build a new world that aligns the personal with the professional, rather than posing them in opposition to each other,

As practitioners who strive to provide meaningful scholarship to students in the most equitable way possible, we view the task of learning through an equity lens. Our educational premise is that there cannot just be treasure for some; there must be treasure for all. Equity is central.

One example of how the central focus on social justice plays out in our programs is evident in the way we deliver instruction. Most of our students live and work far from our physical campus in Prescott, Arizona. The vast array of residences, coupled with the lived experiences of our students, add so much to our program. We capitalize on that diversity. Our effort to better understand the collective rights and obligations of work that are generated from our student body shines through clearly in the projects they produce and through their expressive voices. In the midst of the pandemic, we realized that we would have to make significant adjustments to our program. We changed schedules, granted accommodations, and rapidly incorporated variations to what is normally a formal plan for student capstone presentations, dissertation celebrations, and other expressions of student work that figure in formally to our degree-granting structure. Yet, our eyes never shifted from the mission to encourage equity and to advance education that sustains.

\section{Towards A Just Approach}

Culturally responsive teaching, or teaching with and for justice, challenges didactic pedagogical approaches that are often conflated with whiteness. Teaching outside of the walls of a classroom, through COVID-19 and simultaneously for racial and social justice can and must be done. This begins with being in right and just relationship with students. Given that the latest accounts of anti-Black police violence and protests for Black Lives Matter are experienced differently by students of different racialized identities, it is important that the institution offer racial affinity spaces for students to process and caucus their experiences. In our case, one of us who is white leads an anti-racist affinity group for white faculty and students, and one who is a person of color leads a Black, Indigenous, People of Color (BIPOC) anti-racist affinity group for BIPOC students and faculty. These spaces are generating significant interest, meaningful engagement and interest.

Prescott College, with its mission centered on social justice and environmental stewardship, is well positioned to ally with the Black Lives Matter (BLM) movement. In line with this mission and prior to the current health crisis, the college cultivated Patrisse Cullors, a BLM founder, as a 
faculty member and program director of a novel online MFA in Social and Environmental Arts Practice. The U.S.'s 50-state demonstrations for racial justice have been given particular focus, possibly in part because people have had more time to pay attention to national trends (compounded by disparate racialized health outcomes that COVID-19 has revealed). Rarely has there been as diverse and broad a flow of information and viewpoints on particular social and planetary issues in real time. From newspaper outlets and televised speeches to social media platforms and community spokespersons, the colossal flow of information about COVID-19 has helped to save lives (Finset et al., 2020). This intensely illustrates the importance of making important research available to a wide range of people and through a varied assortment of venues. Access to information that is more open and accessible to nonscholars as well as the scholarly community may have helped to save lives as well as prepare us to be better able to reduce the vulnerability to phenomena such as climate change (Camarillo-Naranjo et al., 2019).

\section{Normalizing the 'New Normal'}

The global pandemic and the deaths of individuals like Breonna Taylor and Ahmaud Arbery remind us that the walls of academia are not the sole place for learning. These types of exposure to how things are connected at a systemic level offer valuable insights for educators, particularly those working in the online platform who have the flexibility to offer more space for deep reflection. Likewise, the brutal death of George Floyd and the collective responses it sparked has created an urgent scene of extensive contemplation about what it means to own/take further accountability for the color of one's skin. In what ways can each of us be held accountable for broader, institutional inequities? In many instances, social distancing and the Black Lives Matter movement force us as educators to reevaluate how we approach every encounter. In many cases, it inspires deep reflection on what is considered normal. As a result, many of us have increased our awareness of how our actions are interconnected and have broader implications.

As revealed in reflection, the pandemic crisis has made visible the degree to which people are inextricably connected to one another regardless of geography. We watched how, in a fleeting matter of weeks, this new contagion swept around the globe, touching every continent. Today, we struggle to absorb the lesson that donning a face mask is not merely for the protection of self, but a crucial step in reducing infection in others. Even as stark differences and health inequities between and among individuals and groups become apparent in this moment, paradoxically, community and the collective matter more than ever. A key challenge for the Prescott College Sustainability Education program orientation is how to recognize community, 
and also to form and reform communities to achieve ecological and socially just aims.

We see that COVID-19 has only exacerbated and elevated racialized and socioeconomic stratification in the United States. According to an NPR story, Dr. Marcella Nunez-Smith, director of the Equity Research and Innovation Center at Yale School of Medicine, noted "We know that these racial ethnic disparities in COVID-19 are the result of pre-pandemic realities. It's a legacy of structural discrimination that has limited access to health and wealth for people of color" (Godoy \& Wood, 2020). It is important in higher education leadership that we continue to address issues of ethnic disparity and find opportunities to address and combat discriminatory stratifying patterns.

The current conditions have forced each of us to reassess not only our lives as individuals and instructors but the doctoral program at Prescott. We have reviewed course titles, descriptions, and course plans. We have evaluated the PhD Program Mission to ensure it aligns with racial justice goals. We offer racial affinity spaces with students and faculty to explore what is emergent for them in their racialized bodies. In the process we examined how any changes feel for the students. We shifted our week-long symposium to a webinar and are striving to make it interactive along with being conscious of being on the screen for long periods of time. All these steps, we feel have helped knit the fabric of a learning community while ensuring safety of social distancing.

\section{Building Community Online}

Though the online platform may be less galvanized than in the traditional face-to-face lecture approach, the professorial lecture approachespecially in times of COVID-19-must give way to greater flexibility. Instructors need to offer new, active student-centered learning opportunities as well as new forms of community. While traditionally the setting of academic learning communities meant a walled classroom, where a professor lectured to students from the front of the room, often from a place of privilege, expecting students to be able to recite their wisdom on an exam, that setting of the physical classroom with its accompanying approach is less effective than engaging students in active learning (Deslauriers et al., 2011; Egelandsdal \& Krumsvik, 2019; Evans, 2013; Freeman et al., 2014). Additionally, Cochran-Smith and Villegas (2015) argued that more enduring and meaningful learning outcomes are generated by "active construction wherein learners drew on prior knowledge and experiences-both individual and sociocultural — as they built new understandings" (p.10).

Beyond valuable networking, creating this sense of community through online collegiality also increases student connection to the content itself (Moore, 2014). Due to the physical separation between instructor and student and among students, there is a perceived barrier to creating community 
in the online platform. However, community can be created, but it requires different approaches, the flexibility offered by the online environment presents an opportunity to shift the way of instruction to active learning and creating community that goes beyond walls.

In these times, our notions of community may shift and need to be reexamined. This includes identifying what constitutes a community and whose community are we including or omitting (either knowingly or unknowingly). As there is a radical shift to online teaching, educators should consider how might communities of learning and engagement look different in times of social distancing, and how educators can foster or increase student connection and learning in virtual environments. In practice, faculty found that moving project evaluations and critiques as well as dissertation defenses online in the spring symposium not only preserved the rigor of the moment for students sharing their work, but also invited participation and perspectives from a far greater number and diversity of peers and colleagues around the world. In future planning, faculty will poll all students to understand what topics the symposium should cover, and what they wish to do or see differently in order to feel their needs and hopes are better being met.

As many institutions move toward an online platform either in response to current conditions or more permanently, finding and leveraging meaningful learning opportunities is vital. Learning in community, to us, also means community engagement. Even in a time of distance learning, this brings immediacy and urgency to our studies. Questions that drive our inquiry broadly include: What does this/my community need? How can I take steps to find out and to take action? What, specifically, do the Black and Brown students wish for?

One of the ways that students can push their learning beyond the classroom and to share their research and interests with the community is via Community Based Experiential Learning (CBEL) projects. CBEL projects create mutually beneficial relationships with their community. Students are afforded the opportunity to connect theory and practice, make learning relevant, and establish peer support, as well as be of service to create a durable, useful outcome for the community. These multifaceted, interdisciplinarity opportunities that are often cited as crucial to meaningful learning, can be difficult to achieve without innovative approaches (MacLeod, 2018).

These types of community-based efforts re-envision the role of education, shifting the narrative of knowledge generated by academics and then applied in a one-way direction (Nicotera et al., 2019). For example, Oscar Medina, a doctoral student, collaborating with his Tierra y Libertad (Land and Freedom) class built a sustainable food system at the K-20 Changemaker Campus near downtown Tucson. The project, Culturally Responsive and Sustaining Barrio School Garden, engaged youth in an adaptive sustainability 
experience at the local and community level by addressing issues related to unsustainable food systems, drought and climate change, nutrition and health, and the reclaiming of traditional farming techniques in the Sonoran Desert.

With CBEL projects, students become the agent of their learning aligning their interests with their community to create a tangible deliverable (B. Santo, Personal Communication, April 15, 2020). Through CBEL endeavors, students apply what they are learning, enhance their problemsolving skills, establish valuable networks, and enhance overall engagement. Additionally, students can take advantage of the capacity of the Internet to expand their network by reaching out to scholars in the field, as well as to local experts. This approach assures that learning goes well beyond the walls of a classroom lecture hall.

What is also key here is to emphasize that while these CBELs have shown great success in strengthening student learning, CBEL experiences are also opportunities to dismantle hierarchies of knowledge production which places the academy at the pinnacle. In alignment with our social justice lens and values, the CBELs intent is to work with communities by using the principles of participatory action research, culturally responsive teaching, critical race theory, and anticolonialism. Students begin by acknowledging the power differentials and structures that may become evident in communitybased work and ensure their learning does not impart unintentional harm (Stoecker, 2016). To design these community-based learning opportunities requires collaboration and active listening, centering what the community may want or need. Through the development and actualization of their CBEL projects, students consider how knowledge can be co-created and recognize the role power and positionality play in community-based learning. These types of community-based projects foster valuable networks and deep connections among the students and members of the community, something that has become even more important during this time of isolation.

\section{A Responsive Shift}

Traditionally, the culminating event at Prescott College is an in-person symposium whereby all students and faculty come together, in person, to share knowledge. The dissertation presentations and keynote speakers anchor the symposium. In response to the need for social distancing created by COVID19 in the Spring of 2020 and to follow social justice values, education, and anti-colonial frameworks, an online Sustainability Education Symposium allowed for scholarly research to be shared more widely, given it was free of cost and accessible to anyone with the technology to join. We were able to do this though the Zoom webinar platform.

Planning and hosting a virtual symposium was both invigorating and challenging, as we thought about how best to preserve key elements of 
experiential learning, collaborative knowledge building, networking or community building, and personal engagement that comes with the symposium at Prescott College. One workshop focused on not only sharing our experiences of decolonizing pedagogy, but to also enact it through digital engagement and collaborative knowledge building and meaning-making. Several technological applications, such as Google Docs, Kahoot, and Padlet, served as a virtual springboard for collaboration and sharing. The two keynote speakers for the event were BIPOC women who both spoke to power and privilege in their talks, with anti-racist and decolonizing orientations. Symposium turnout was high for our tight-knit community (averaging about 100 people per session). Dissertation committee members showed up in full force across institutions, states, and countries. Given its broad reach, this online symposium was so well attended, we began to wonder why we did not do this virtually in the past. The pandemic and its laying bare racial inequities have fundamentally altered education and the role professors play in the lives of students. Leading from the heart, committing to explicit anti-racist teaching and learning, and meeting students where they are, we believe, is a valuable first step toward lasting and meaningful learning. We are striving to continue to live these values as this challenging time of uncertainty continues.

\section{Conclusion}

The COVID-19 pandemic and subsequent global response sparked the conception of this manuscript. Yet a series of events from the killing of George Floyd to nationwide Black Lives Matter protests to the more recent racist attacks and death threats on one of our Prescott College professors have invited increased urgency to our writing. As professors in a Sustainability Education doctoral program, we strive to build leadership skills that foster environmental and social justice values and pedagogies in sustainability education. In order to shift from these theoretical frameworks towards direct action, we have examined how this shows up in our teaching, with particular emphasis on how as educators, we have responded to the events and movements of 2020 . We have hope that by offering examples of our commitment for change - beyond performativity - holds both our institution and other Predominantly White Institutions accountable for enacting a pedagogy that centers compassion and justice.

Embedded in the intersection of justice and compassion in teaching, Michalinos Zembylas (2017) wrote "Pedagogies of compassion are 'critical,' in that they aim to transform students and educators as well as the educational institutions and the communities that they serve by identifying and challenging sentimentalist and moralistic discourses that often obscure inequality and injustice" (p. 174). Similar to Zembylas's pedagogy of compassion, the Sustainability Education Doctoral Learning Outcomes are deeply rooted in 
social justice and (re)humanizing pedagogy. While we are committed to leading with the heart, building community, and being intentionally anti-racist in our curriculum and instructional practices, what is key here is to acknowledge that it is not enough to say we have arrived or are purportedly woke, but instead, will continue to strive for racial, social, and environmental justice.

Many institutions of higher education are finding themselves in a radically shifted political, social, and cultural milieu of 2020. There is pressure to move courses fully online, consider how systemic racism shows up, and plan for what is deemed the new normal. It is our hope to offer the reader some of the lessons we have learned from teaching in 2020 that challenge the dominant neoliberal and racist underpinnings of higher education, while fostering meaningful and transformative learning experiences.

\section{References:}

1. Camarillo-Naranjo, J. M., Álvarez-Francoso, J. I., LimonesRodríguez, N., Pita-López, M. F., \& Aguilar-Alba, M. (2019). The global climate monitor system: From climate data-handling to knowledge dissemination. International Journal of Digital Earth, 12(4), 394-414. https://doi.org/10.1080/17538947.2018.1429502

2. Cochran-Smith M, \& Villegas, A.M. (2015). Framing teacher preparation research: An overview of the field, part 1. Teaching Education, 66(1), 7-20. https://doi.org/10.1177/0022487114549072

3. Dhilla, S. J. (2017). The role of online faculty in supporting successful online learning enterprises: A literature review. Higher Education Politics \& Economics, 3(1), 3.

4. Dereshiwsky, M. (2016). Equity in the online classroom: Adolescent to adult. In Social Justice Instruction (pp. 33-42). Springer International Publishing. https://doi.org/10.1007/978-3319-12349-3_4

5. Deslauriers, L., Schelew, E.,\& Wieman, C. (2011). Improved learning in a large-enrollment physics class. Science Education International, 322(6031), 862-864. https://doi.org/10.1126/science.120 1783

6. Egelandsdal, K., \& Krumsvik, R. J. (2019). Clicker Interventions: Promoting Student Activity and Feedback at University Lectures. In A. Tatnall (Ed.), Encyclopedia of Education and Information Technologies (pp. 1-15). Springer International Publishing. https://doi. org/10.1007/978-3-319-60013-0. 
7. Evans, C. (2013). Making sense of assessment feedback in higher education. Review of Educational Research, 83(1), 70-120. https://doi.org/10.3102/0034654312474350

8. Finset, A., Bosworth, H., Butow, P., Gulbrandsen, P., Hulsman, R. L., Pieterse, A. H., ... \& van Weert, J. (2020). Effective health communication-a key factor in fighting the COVID-19 pandemic. Patient Education and Counseling, 103(5), 873.

9. Foster, L., Neuer Colburn, A., \& Briggs, C. (2018). Language \& online learning: Inform, inspire and engage virtual learning communities. The Journal of Counselor Preparation and Supervision, 11(1). https://repository.wcsu.edu/jcps/vol11/iss1/6

10. Fox, H. L. (2017). What Motivates Community College Students to Enroll Online and Why It Matters. Insights on Equity and Outcomes. Issue 19. Office of Community College Research and Leadership.

11. Freeman, S., Eddy, S. L., McDonough, M., Smith, M. K., Okoroafor, N., Jordt, H., \& Wenderoth, M. P. (2014). Active learning increases student performance in science, engineering, and mathematics. Proceedings of the National Academy of Sciences, 111(23), 8410-8415.

12. Godoy, M., \& Wood, D. (2020, May 30). What do Coronavirus Racial Disparities Look like State by State? https://www.npr.org/sections/healthshots/2020/05/30/865413079/whatdo-coronavirus-racialdisparities-look-like-state-by-state

13. Jackson, T. (2020, March). COVID-19 and videoclassism: Implicit bias, videojudgment, and why I'm terrified to have you look over my shoulder. LinkedIn. https://www.linkedin.com/pulse/covid-19videoclassism-implicit-bias-videojudgment-why-jackson/

14. Lucero, J. L., Evers, J., Roark, J., \& Parker, D. (2017). Using community-based research to improve BSW students' learning in community practice: Bringing the macro into focus for traditional and distance learners. Journal of Teaching in Social Work, 37(3), 260-279. https://doi.org/10.1080/08841233.2017.1320621

15. MacLeod, M. (2018). What makes interdisciplinarity difficult? Some consequences of domain specificity in interdisciplinary practice. Synthese, 195(2), 697-720. https://doi.org/10.1007/s11229-016-1236-4

16. Moore, R. L. (2014). Importance of developing community in distance education courses. TechTrends, 58(2), 20-24. https://doi.org/10.1007/s11528-014-0733-X 
17. Nicotera, N., Cutforth, N., Fretz, E., \& Thompson, S. S. (2019). Dedication to community engagement: A higher education conundrum?. Journal of Community Engagement and Scholarship, $4(1), 5$.

18. Stoecker, R. (2016). Liberating service learning and the rest of higher education civic engagement. Temple University Press.

19. Swartz, H. (April 2020). Learning in the age of COVID-19. The Scholarly Teacher: Authentic Teaching and Connected Engaging Students. https://www.scholarlyteacher.com/post/authenticteaching-and-connected-learning-in-the-age-of-covid-19

20. van Oostveen, R., DiGiuseppe, M., Barber, W., Blayone, T., \& Childs, E. (2016). New conceptions for digital technology sandboxes: Developing a fully online learning communities (FOLC) model. In Proceedings of EdMedia 2016-World Conference on Educational Media and Technology (pp. 665-673). Vancouver, BC, Canada: Association for the Advancement of Computing in Education (AACE). Retrieved May 23, 2020 from https://www.learntechlib.org/primary/p/173015/.

21. Zembylas, M. (2017). In search of critical and strategic pedagogies of compassion: Interrogating pity and sentimentality in higher education. In P. Gibbs (Ed.) The Pedagogy of Compassion at the Heart of Higher Education (pp. 173-187). Springer. 